hand, the collection of a few short-lived individuals of high-density species should not have a negative effect on a population. If the habitat of any species is destroyed, however, it will necessarily disappear from that spot, and if the species is confined to the habitat under destruction, it will vanish for ever.

In the case of the shrew Crocidura desperata, it is the extremely endangered, relict forest in southern Tanzania about which we should be concerned, not the first two specimens ever collected by biologists. (To clarify the point for the record, the discovery that the specimens represented a new species occurred only 2 years later in the laboratory. Such cryptic mammals cannot be properly identified in the hand alive.) In this particular case and in many others, the preservation of the habitat is the only measure that makes any ecological sense. We decided to announce the discovery of this new species in a conservation journal such as Oryx as an example of the many small mammals that are described each year from the tropics but rarely receive any attention from the public, although they add considerably to the vertebrate diversity of the threatened forests.

In my view $\mathrm{Mr}$ Lever has glorified the recent description of the shrike, Laniarius liberatus, too much. One should bear in mind that the authors were able to analyse, in a comparative manner, the tissues obtained from the single bird, which was later released, by making use of existing bird collections in research museums. Therefore, their procedure should be recognized as an exceptional case and not considered to be a model. Also, they presented no evidence that the shrike, released in Somalia after 14 months of captivity and a shuttle to Germany, survived and reproduced in the new, unfamiliar habitat. Finally, the reproduction of an individual is the only aspect of its biology that is really important for the survival of a species.

It is my impression that the philosophical problems involved in nature conservation and the collection of scientific specimens have not yet been properly addressed. Nevertheless their discussion in a scientific (rather than in a solely moralistic) context is needed in order to evolve toward an understanding of how best to preserve our flora and fauna.

Rainer Hutterer, Museum Alexander Koenig, Adenauerallee 162, D5300 Bonn 1, Germany.

\section{Romer's tree frog and Hong Kong airport}

The sources of the short item entitled 'Endemic tree frog at risk' (Oryx, 25, 192) seem to imply that the island of Chek Lap Kok, which is to be razed by the airport scheme, is an area of major ecological importance with '... freshwater marshes, excellent mangrove swamps, and habitats for 32 terrestrial vertebrate species.' Nothing could be further from the truth, as Chek Lap Kok has a long history of human impact and the two mangroves are postage-stamp size. Moreover, most of the vertebrates are birds, which are able to disperse to other, less-impacted areas. The value of Chek Lap Kok lies, as your article points out, in the presence of Romer's tree frog, which is found on only two other islands (both considerably larger than Chek Lap Kok). The good news is that since your article was published the Royal Hong Kong Jockey Club Charities have given Hong Kong University $\$ \mathrm{HK} 470,000$ to research the biology of Romer's tree frog and its associated wetland habitat, with the aim of producing a conservation and management plan for the frog. The money will be used to fund a Ph.D. student (Michael Lau) who will undertake the project under my supervision. The bad news is that the Port and Airport Development Scheme is one of the biggest (if not the biggest) and most expensive (estimated $\$ \mathrm{HK} 127$ billion) civil engineering projects ever undertaken anywhere in the world; the Hong Kong government has not yet provided any money for ecological mitigation, despite the fact that site work has started. We are pleased that the Jockey Club has provided money for research on Romer's tree frog, but disturbed that a charity must fill this breech when the responsibility lies with the government.

David Dudgeon, Department of Zoology, Hui Oi Chow Science Building, The University of Hong Kong, Hong Kong. 